\title{
Abrasion Resistance of Thermally Treated Beech Wood
}

\section{Rastislav Lagaňa}

Department of Wood Science, Faculty of Wood Sciences and Technology, Technical University in Zvolen, Slovakia

\begin{abstract}
The study focused on the abrasion resistance of beech wood thermally treated at high temperatures. A standard test for determining abradability, according to ISO 4649, was used. We studied factors such as the anatomical direction, temperature of treatment, and duration of treatment, as well as their effects on abrasion resistance performance. Four temperature levels (20 ${ }^{\circ} \mathrm{C}, 160{ }^{\circ} \mathrm{C}, 180^{\circ} \mathrm{C}$, and $200{ }^{\circ} \mathrm{C}$ ) and three durations of treatment ( $1 \mathrm{~h}, 3 \mathrm{~h}$, and $5 \mathrm{~h}$ ) were used. Results showed that the anatomical direction was not a significant factor, but there was a strong influence of temperature and duration of treatment, respectively, on abrasion resistance. Due to a strong correlation between moisture content and abrasion resistance, the equilibrium moisture content of thermally treated wood could be used for the prediction of abrasion resistance
\end{abstract}

Keywords: Abradability, thermal treatment, beech, abrasion resistance

\section{${ }^{*}$ Correspondence to Author:}

Rastislav Lagaňa

Technical University in Zvolen, T. G. Masaryka 24, 96001 Zvolen, Slovakia Email: lagana@ tuzvo.sk

How to cite this article:

Rastislav Lagaňa. Abrasion Resistance of Thermally Treated Beech Wood. International Research Journal of Materials Sciences and Applications, 2020 3:10.

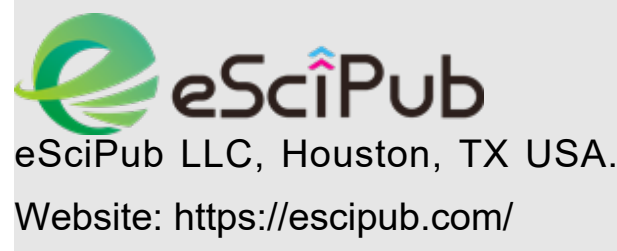




\section{INTRODUCTION}

Beech is one of the most widespread wood species in Central Europe, and compared to other wood species, it has very good wear resistance (Brozek et al. 2017) ${ }^{1}$. Beech wood has growing issues such as reaction wood, red heartwood, poor resistance to fungi, and a problem with dimensional stability. A hightemperature thermal treatment affects the wood's chemical, physical, and mechanical properties, and it has the potential to enhance the wood's properties while maintaining its wear resistance capacity (Coelho et al. 2017) ${ }^{2}$. Effective utilization of thermally treated wood requires well-defined changes in wood properties (Hill 2006, Hamiyet et al. 2018) (3,4. $^{3}$. Often, treated beech wood is used as decking or flooring material, where abrasion performance plays an important role, but abrasion performance has not been fully investigated. This study focused on the effect of thermal treatment on the abradability of the treated surface of beech wood and analyzed the influence of different temperatures and durations of treatment on these properties.

\section{MATERIAL AND METHODS}

Clear tangential and radial boards of dimensions $50 \times 20 \times 500 \mathrm{~mm}^{3}(\mathrm{R} \times \mathrm{T} \times \mathrm{L}$ or $\mathrm{T} \times \mathrm{R} \times \mathrm{L})$ were cut from air-dried beech wood boards (Fagus sylvatica L.). Before thermal treatment, the boards were oven-dried. Three temperature levels in the oxidizing atmosphere $\left(160^{\circ} \mathrm{C}\right.$, $180^{\circ} \mathrm{C}$, and $200^{\circ} \mathrm{C}$ ) and three treatment durations ( $1 \mathrm{~h}, 3 \mathrm{~h}$, and $5 \mathrm{~h}$ ) were used. After the treatment, the boards were placed in a conditioning chamber at a temperature of $20^{\circ} \mathrm{C}$ and relative humidity of $65 \%$ until they reached equilibrium moisture content. The final column specimens $(\varnothing 16 \times 15 \mathrm{~mm})$ were drilled from the boards using a $16 \mathrm{~mm}$ plug cutter drill bit, and tested shortly after. A group of 15 column specimens was tested for each thermal treatment in the radial direction of abrasion, and the other group of 15 specimens was tested in the tangential direction. Abrasion resistance was tested by moving a column specimen across the surface of 120-grit sandpaper mounted on a rotating drum according to ISO 4649 . Since the abrasion wear of wood is dependent on applied surface pressure (Ohtani et al. 2003) $)^{5}$, a constant load was maintained on the wood specimens during the abrasion test. The abradability $t_{m}$ was expressed as a change of mass after moving a specimen across half of the rotating drum length (Eq. 1):

$$
t_{m}=\frac{m_{1}-m_{2}}{m_{1}} .100 \%
$$

where $m_{1}$ is the mass of a specimen before an abrasion test and $m_{2}$ is the mass of a specimen after the test. Further, specimens were ovendried to evaluate their moisture content.

The significance of three factors - anatomic direction, duration of the treatment, and temperature of the treatment - were determined by the ANOVA procedure using Statistica software.

\section{RESULTS AND DISCUSSION}

A Shapiro-Wilk normality test proved the normal distribution of abrasion resistance $t_{m}$ data. ANOVA showed that the anatomical direction did not significantly affect the abrasion resistance $\left(F_{1,387}=3.56, p=0.060\right)$, and thus the rate of abradability change (percent of change per hour of treatment) seemed to be higher in the radial direction (Figure 1). In contrast, Autin et al. $(2015)^{6}$ reported significant changes in the tangential direction only when using a different abrasion test setup. Our data showed that the temperature and duration of treatment were very significant $\left(F_{2,387}=180.50, p<0.001\right.$ and $F_{3,387}$ $=451.98, p<0.001$, respectively). Abrasion resistance decreased after the thermal treatment. In line with the shaker test results provided by Welzbacher et al. $(2009)^{7}$, the abradability of wood doubled from $9 \%$ for untreated wood to $18 \%$ for wood treated at 200 ${ }^{\circ} \mathrm{C}$ for $5 \mathrm{~h}$. Abradability increased with the duration of treatment at each temperature (Fig. 1).

The moisture content of the wood was rather low and was not at the level of equilibrium moisture content. The samples most probably underwent 
some drying during the plug cutter drilling and abrasion test sanding.

The density of wood decreased after the treatment. The temperature was a significant factor influencing the density $\left(F_{2,387}=101.9, p<\right.$ 0.001 ). Due to lack of homogeneity between the groups, the main change in density was observed at $200^{\circ} \mathrm{C}$ (Fig. 2).

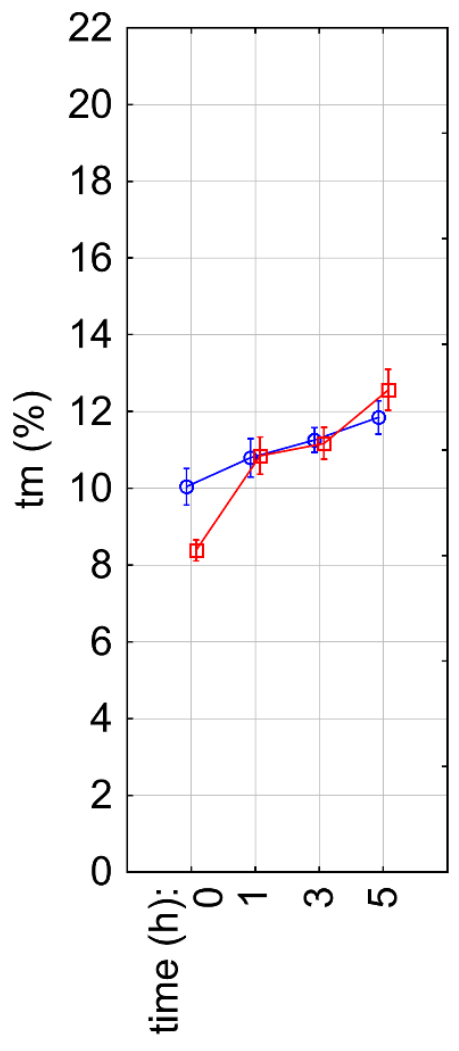

$\mathrm{T}\left({ }^{\circ} \mathrm{C}\right): 160$

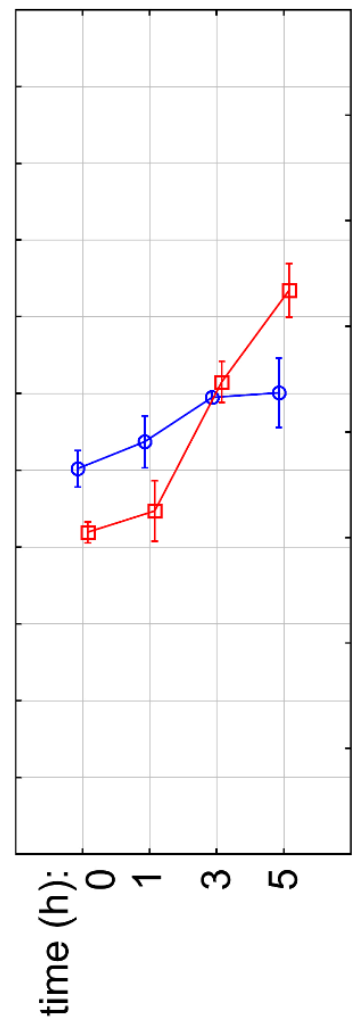

$\mathrm{T}\left({ }^{\circ} \mathrm{C}\right): 180$

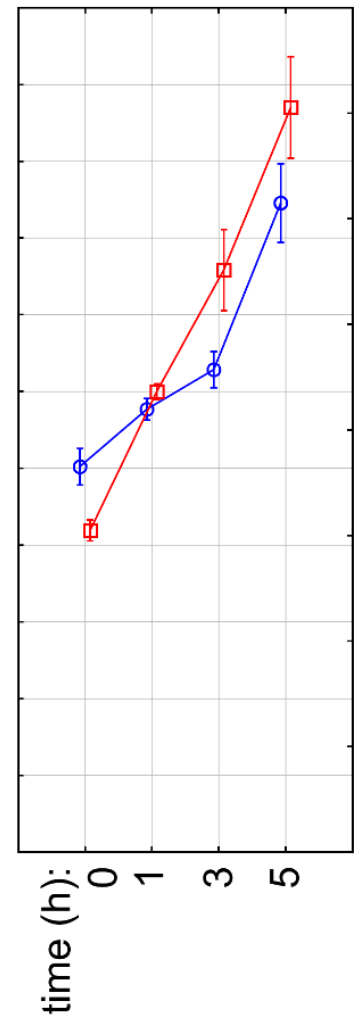

$\mathrm{T}\left({ }^{\circ} \mathrm{C}\right): 200$

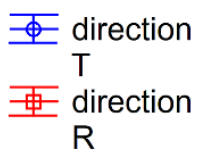

$\mathrm{R}$

Figure 1: Abradability of thermally treated beech wood. Bars stand for the $95 \%$ confidence level.

Table 1: Results of abradability $t_{m}$, moisture content MC, and density of thermally treated beech wood. The standard deviation is in brackets.

\begin{tabular}{llllll}
\hline $\mathrm{T}\left[{ }^{\circ} \mathrm{C}\right]$ & time $[\mathrm{h}]$ & \# of specimens & $\mathrm{tm}_{\mathrm{m}}[\%]$ & $\mathrm{MC}[\%]$ & density $\left[\mathrm{g} / \mathrm{cm}^{3}\right]$ \\
\hline $\mathbf{2 0}$ & 0 & $15+15$ & $9.19(1.22)$ & $4.95(0.28)$ & $0.695(0.017)$ \\
\hline $\mathbf{1 6 0}$ & 1 & $15+15$ & $10.83(0.87)$ & $4.70(0.18)$ & $0.702(0.027)$ \\
$\mathbf{1 6 0}$ & 3 & $15+15$ & $11.22(0.66)$ & $4.17(0.17)$ & $0.701(0.008)$ \\
$\mathbf{1 6 0}$ & 5 & $15+15$ & $12.20(0.94)$ & $3.91(0.18)$ & $0.685(0.016)$ \\
\hline $\mathbf{1 8 0}$ & 1 & $15+15$ & $9.84(1.60)$ & $3.84(0.19)$ & $0.671(0.018)$ \\
$\mathbf{1 8 0}$ & 3 & $15+15$ & $12.10(0.74)$ & $3.44(0.22)$ & $0.696(0.020)$ \\
$\mathbf{1 8 0}$ & 5 & $15+15$ & $13.35(1.97)$ & $3.38(0.23)$ & $0.686(0.018)$ \\
\hline $\mathbf{2 0 0}$ & 1 & $15+15$ & $11.77(0.50)$ & $3.45(0.22)$ & $0.681(0.019)$ \\
$\mathbf{2 0 0}$ & 3 & $15+15$ & $13.87(1.96)$ & $2.70(0.18)$ & $0.672(0.013)$ \\
$\mathbf{2 0 0}$ & 5 & $15+15$ & $18.16(2.45)$ & $2.13(0.25)$ & $0.636(0.017)$ \\
\hline
\end{tabular}




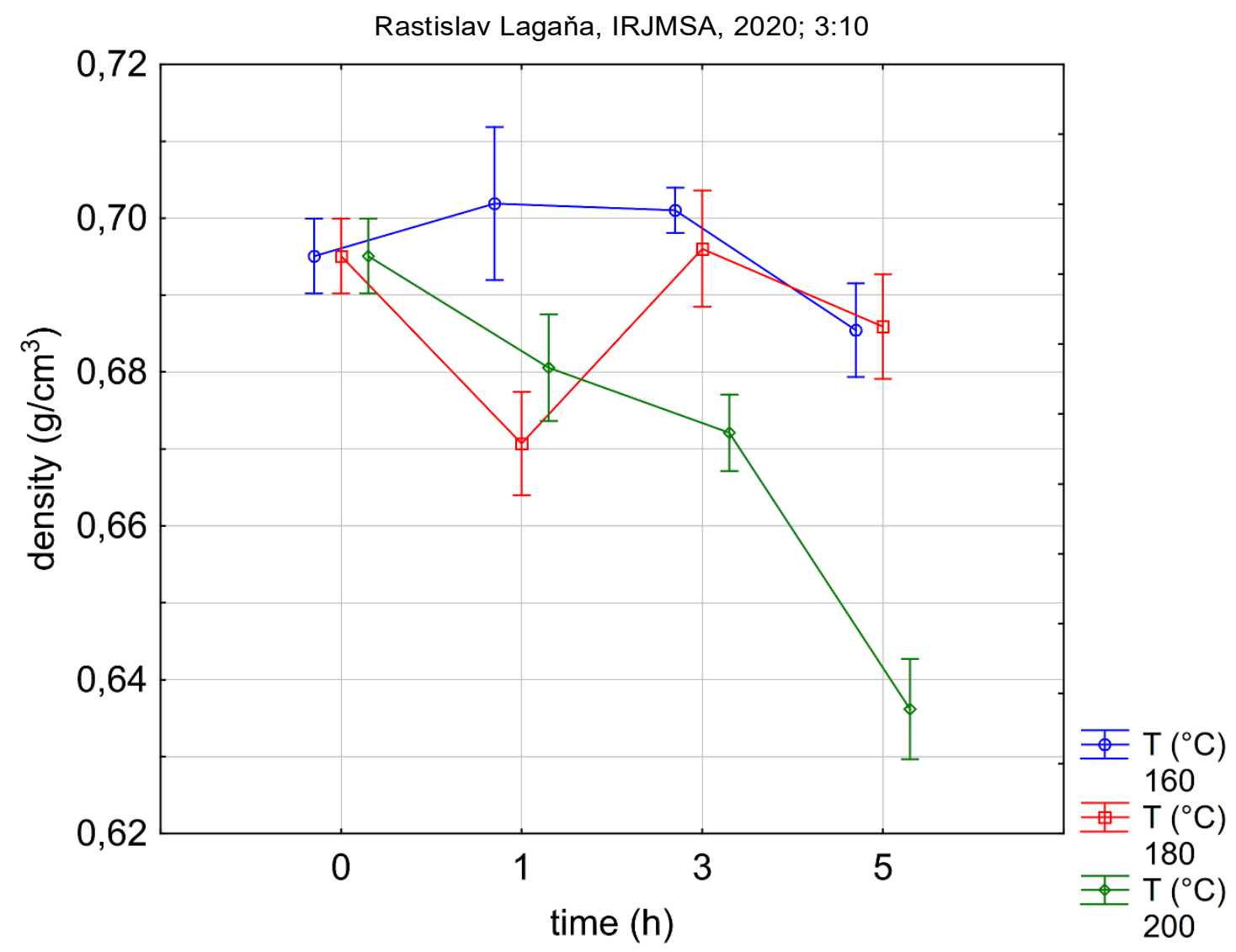

Figure 2: Density of thermally treated beech wood. Bars stand for the $95 \%$ confidence level.

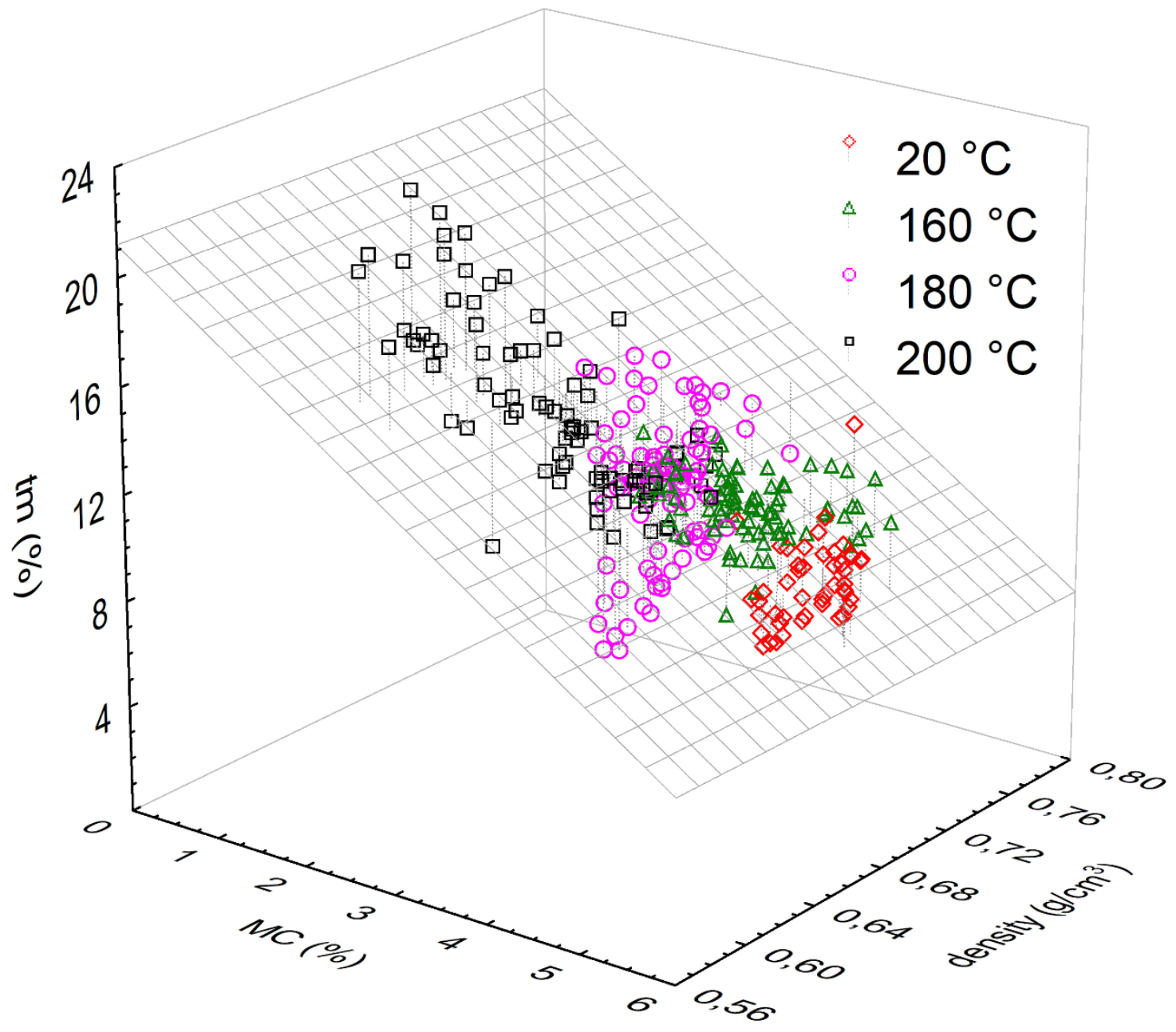

Figure 3: Linear approximation of abradability $t_{m}$ for moisture content and wood density. 
Duration of treatment was also a significant factor $\left(F_{3,387}=63.1, p<0.001\right)$.

Abradability, moisture content, and density of the thermally treated beech wood after abrasion tests are summarized in Table 1 . Since the effect of the anatomical direction was not significant, the data for both anatomical directions and the same treatment were grouped. The optimal treatment of beech wood is characterized by a temperature of $180{ }^{\circ} \mathrm{C}$ and duration of $1 \mathrm{~h}$. Although the abrasion resistance dropped by 7 $\%$ compared to untreated wood, the reported improvement of other properties such as dimensional stability and fungi resistance (Bal 2015, Boonstra et al. 2006) $)^{8,9}$ outweigh this change. Beech wood, treated at this condition, performed comparably to untreated hornbeam (Brozek 2017) ${ }^{1}$.

The correlation coefficient between abradability and moisture content $\left(R^{2}=0.630\right)$ was significant, while that between abradability and wood density was not significant $\left(R^{2}=0.190\right)$ at the significance level $\alpha=0.05$. Linear approximation of abradability confirmed that the change of abrasion resistibility is more influenced by the change in moisture content than the change in the density (Fig. 3).

Therefore, the moisture content could be used for the prediction of the abrasion resistance of thermally modified beech wood.

\section{CONCLUSIONS}

The abrasion resistance of thermally treated beech wood was examined, and the effect of treatment was investigated. The following conclusions were proposed.

1. High-temperature thermal treatment significantly influences the abrasion resistance of beech wood, while the effect of the anatomical direction of sanding was not significant.

2. Both temperature and duration of treatment significantly affected abrasion performance.

3. The moisture content of the treated beech wood could be used as a good prediction tool for the estimation of abrasion resistibility.

Despite the effect of thermal treatment on abrasion resistance, treated beech wood can be used for decking and flooring. Optimal thermal treatment in an oxidizing atmosphere is at a temperature of $180^{\circ} \mathrm{C}$ for 1 hour.

\section{ACKNOWLEDGMENTS}

This work was supported by the Slovak Research and Development Agency under contract No. APVV-16-0177. Special appreciation goes to Peter Bazala for preparing test materials and performing abrasion tests.

\section{REFERENCES}

1. Brožek M. Abrasive wear resistance of selected woods. Research in Agricultural Engineering, 2017; 63(2): 91-97. https://doi.org/10.17221/7 4/2 015-RAE.

2. Coelho MU, Del Menezzi C, Souza MR. Abrasion Resistance of Pinus Wood Subjected to Thermomechanical Treatments. Pro Ligno, 2017; 13(4), 94-100.

3. Hill C. Wood Modification: Chemical, Thermal and Other Processes, John Wiley and Sons, Chichester 2006.

4. Hamiyet K, Sema A, Kübra G. Effect of heat treatment on the mechanical properties and dimensional stability of beech wood. Journal of Advanced Technology Sciences, 2018; 6, 820830.

5. Ohtani T, Kamasaki K, Tanaka C. On abrasive wear property during three-body abrasion of wood. Wear, 2018; 255, 60-66.

6. Autin A, Korkut $S$, As N, Ünsal O, Gündüz G. Effect of Heat Treatment of Wild Cherry Wood on Abrasion Resistance and Withdrawal Capacity of Screws. Drvna Industrija, 2015; 66(4), 297-303. https://doi.org/10.5552/drind.2015.1440.

7. Welzbacher ChR, Brischke Ch, Rapp AO, Koch S, Hofer S. Performance of thermally modified timber (TMT) in outdoor application - durability, abrasion and optical appearance. Drvna Industrija, 2009; 60(2), 75-82.

8. Bal BC. Physical properties of beech wood thermally modified in hot oil and in hot air at various temperatures. Maderas. Ciencia y tecnología, 2015; 17(4), 789-798. http://dx.doi. org/10.4067/S0718-221X2015005000068

9. Boonstra M, van Acker J, Kegel E, Stevens M. Optimisation of a two-stage heat treatment process: durability aspects. Wood Science and Technology, 2006; 41, 31-57

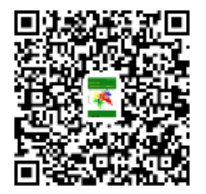

Https:/escipub.com/international-research-journal-of-materials-sciences-and-applications/ 